\title{
Deposition of ZnO Nanopraticles on MWCNTs for Glucose Oxidase Direct Electrochemistry
}

\author{
M. Jafari ${ }^{1}$, A.A. Khodadadi ${ }^{1}$, Y. Mortazavi $^{2}$, H. Ghorchian ${ }^{3}$ \\ ${ }^{1}$ School of Chemical Engineering, College of Engineering, University of Tehran, Tehran, Iran, \\ Mortazav@ut.ac.ir \\ ${ }^{2}$ Nanoelectronics Centre of Excellence, University of Tehran, Tehran, Iran \\ ${ }^{3}$ Institute of Biochemistry \& Biophysics, University of Tehran, Iran
}

\begin{abstract}
$\mathrm{ZnO}$ nanopaticles on multiwall carbon nanotubes (MWCNTs) were prepared by a microwave assisted hydrothermal method, modified by ionic liquid (IL) and used for stabilization of glucose oxidase and its direct electrochemistry. The structure and composition of ZnO/MWCNTs sample was characterized by $\mathrm{x}$-ray diffraction. Cyclic voltammetry was used to evaluate the electrochemical performance of ZnO/MWCNTs nanocomposites modified electrode. IL/ZnO/MWCNTs modified electrode was found to have the best performance for immobilization of glucose oxidase.
\end{abstract}

Key words: Glucose biosensor, carbon nanotubes, $\mathrm{ZnO}$ nanoparticles

\section{Introduction}

Numerous efforts have been focused on the development of new materials to design electrochemical biosensors. Among these materials, CNTs have been extensively used in electrochemical biosensor conformation [1]. Recently most of the researches in the field have intended to modify CNTs with other nanomaterials such as metal and metal oxide particles. These modified composite materials possess the properties of ingredients, or even with a synergistic effect. Electrochemical sensors based on metal oxide- modified electrodes have been used to analyze biomolecules. However, they have the disadvantage of poor electrical conductivity that limits their applications. To modify this property the electroactive metal oxides are loaded onto CNTs. CNT can lead to a better dispersion of oxide nanoparticles beside, it can improve transferring of electrons in order to straight conducting pathway [2].

$\mathrm{ZnO}$ is a biocompatible with a high isoelectric point (IEP) of about 9.5 which make it suitable for absorption of low IEP proteins such as glucose oxidase ( $\mathrm{GOx}, \mathrm{IEP}=4.2)$. In this work, microwave-assisted aqueous solution method was used to prepare GOx/ZnO/MWCNTs to be used for fabrication of a glucose biosensor.

\section{Experimental}

Multi walled carbon nanotubes (MWCNTs) (10$20 \mathrm{~nm}$ diameter, 10-30 $\mu \mathrm{m}$ length with $>95 \%$ purity) were purchased from Neutrino Co.
$\mathrm{KH}_{2} \mathrm{PO}_{4}, \quad \mathrm{~K}_{2} \mathrm{HPO}_{4}, \mathrm{NaOH}$, and $\mathrm{Zn}(\mathrm{Ac})_{2} \cdot \mathrm{H}_{2} \mathrm{O}$ were purchased from Merck, while GOx (EC 1.1.3.4, Type X-S from Aspergillus niger) and 1butyl-3- methylimidazolium tetrafuoroborate ([BMIM]BF4) were purchased from SigmaAldrich. All other reagents were of analytical grade. Deionized water was used for preparation of all aqueous solutions. MWCNTs were functionalized by acid treatment, dissolved in deionized water under ultrasonic agitation for $30 \mathrm{~min}$ and after adding $\mathrm{Zn}(\mathrm{Ac})_{2} \cdot 2 \mathrm{H}_{2} \mathrm{O}$ and $\mathrm{NaOH}$ to addjust $\mathrm{pH}$, the solution was placed in the microwave oven [3]. $3 \mu \mathrm{L}$ of $\mathrm{ZnO} / \mathrm{MWCNTs}$ ( $2 \mathrm{mg} / \mathrm{mL}$ dispersed in DMF) was dropped on the electrode surface. After drying it was immersed in the ionic liquid (IL) and GOx solution $(5 \mathrm{mg} / \mathrm{mL}$ dissolved in PBS, $\mathrm{pH}=7,0.05$ M) for 9 and $12 \mathrm{~h}$ respectively and kept at $4^{\circ} \mathrm{C}$. After each immersion, the electrode was rinsed with water to remove the weakly adsorbed IL and GOx.

\section{Results}

XRD pattern of ZnO/MWCNTs is shown in Fig. 1. The peak at $30.06^{\circ}$ belongs to graphitic structure of MWCNTs and the peaks at $37.04^{\circ}$, $40.13^{\circ}, 42.34^{\circ}, 55.77^{\circ}, 66.77^{\circ}, 74.48^{\circ}$ and $78.96^{\circ}$ belong to the $\mathrm{ZnO}$. 


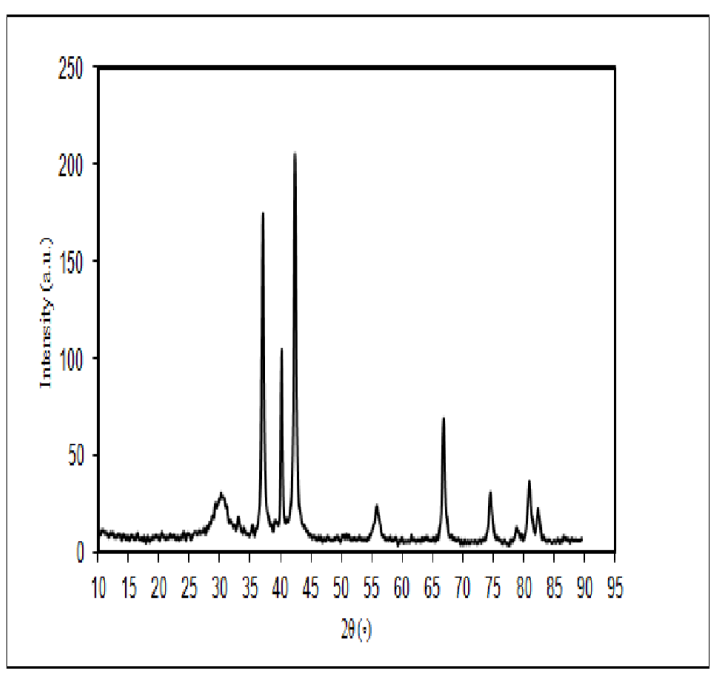

Fig. 1. XRD pattern of ZnO/MWCNTs.

Figure 2 shows cyclic voltametery (CV) of different electrodes in $0.05 \mathrm{M}$ PBS at a scan rate of $50 \mathrm{mV} / \mathrm{s}$. According to this figure electrostatic interaction of $\mathrm{ZnO}$ with active center of GOx, generate electrochemical redox peak in potential range from -0.2 to -0.8 $\mathrm{V}$. Addition of IL to the surface of electrode improves this redox peak. The current improvment is due to the high conductivity of the IL. Immobilization of GOx exhibited an increase in current compared to the ZnO/MWCNTs electrode.

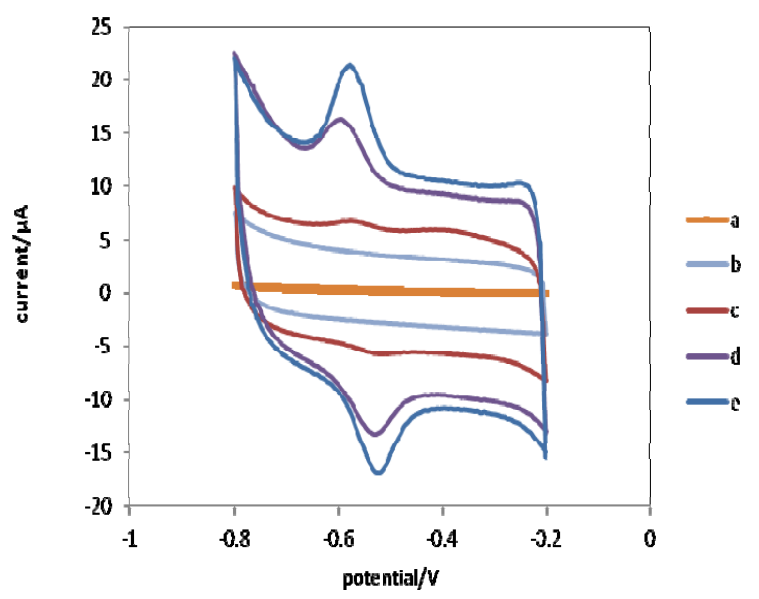

Fig. 2. Cyclic voltammograms of different modified electrodes at $50 \mathrm{mV} / \mathrm{s}$ in $0.05 \mathrm{M} P B S$ a: bare $b: \mathrm{ZnO} /$ MWCNTs c: GOx/MWCNTs d: GOx/ZnO/MWCNTs e: GOX/IL/ZnO/MWCNTs.

The effect of $\mathrm{pH}$ on the potential peak position was investigated and the linear relation was obtained with correlation of $\mathrm{R}^{2}=0.998$ (Fig. $3,4)$. The slope of linear plot $(-0.06 \mathrm{~V})$ shows a good agreement with the theoretical results, i.e. $-0.059 \mathrm{~V}$ [4]. Figure 3 shows a negative shift in formal potential by increasing the $\mathrm{pH}$. According to Fig. 4 the largest current peak was obtained at $\mathrm{pH}=7$, thus, it was chosen as the optimum $\mathrm{pH}$.

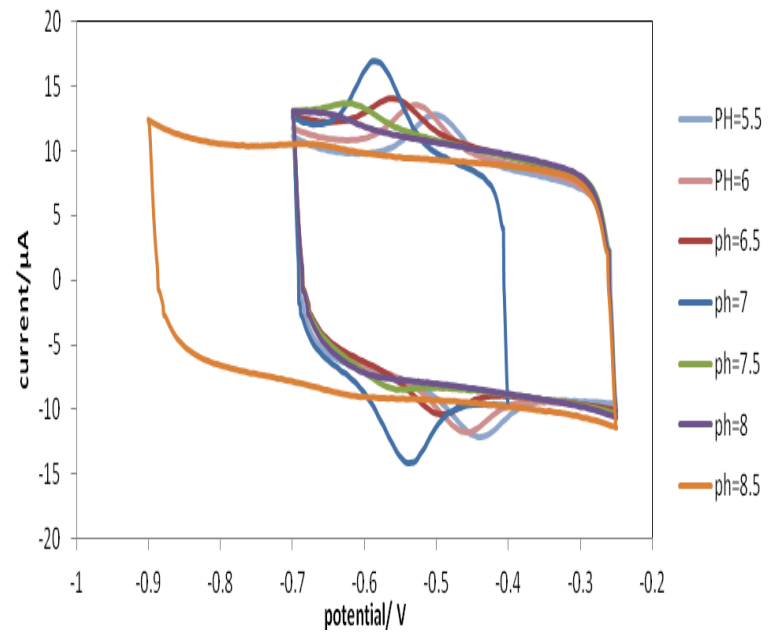

Fig. 3. Cyclic voltammograms of GOx/IL/ZnO/MWCNTs in 0.05 M PBS at pH. 5.5, 6.0, $6.5,7.0,7.5,8.0$ and 8.5 , from right to left respectively.

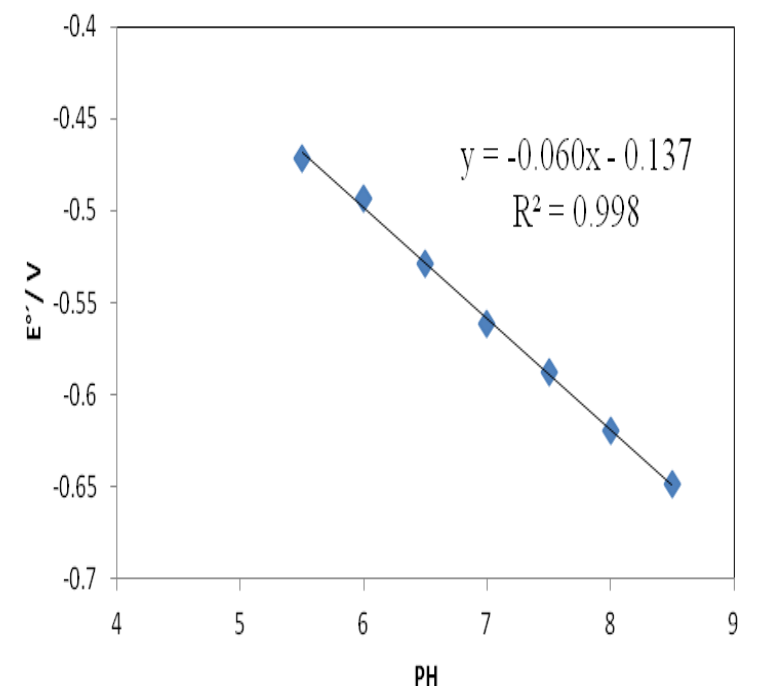

Fig. 4. Plot of $E^{\circ}$ versus $p H$. 


\section{References}

[1] M.M. Rahman, A. Umarb, K. Sawada, journal of Sensors and Actuators B 137, 327-333 (2009); doi: 10.1016/j.snb.2008.10.060

[2] W. Zhang, B. $\mathrm{Xu}$ and L. Jiang, Journal of Materials Chemistry 20,6383-6391(2010); doi: 10.1039/b926341a

[3] N. Faal Hamedani, A.R. Mahjoub, A. A. Khodadadi, Y. Mortazavi, journal of Sensors and $\begin{array}{lllll}\text { Actuators } \quad B, & 156 & 737-742 & \text { (2011); }\end{array}$ doi:10.1016/j.snb.2011.02.028
[4] Nak M. Tasviri, H. A. Rafiee-Pour, H. Ghourchian, M. R. Gholami, Journal of Molecular Catalysis B: Enzymatic 68 206-210 (2011); doi:10.1016/j.molcabtab.2010.11.005 